Москвин В.А., Москвина Н.В. Психофизиологические аспекты эмоционально-волевой подготовки к экстремальным ситуациям (на примере восточных единоборств) // Экстремальная деятельность человека. - 2016. № 1 (38). - C. $30-33$.

\title{
ПСИХОФИЗИОЛОГИЧЕСКИЕ АСПЕКТЫ ЭМОЦИОНАЛЬНО- ВОЛЕВОЙ ПОДГОТОВКИ К ЭКСТРЕМАЛЬНЫМ СИТУАЦИЯМ (НА ПРИМЕРЕ ВОСТОЧНЫХ ЕДИНОБОРСТВ)
}

Москвин Виктор Анатольевич - доктор психологических наук, профессор кафедры психологии РГУФКСМиТ

Москвина Нина Викторовна - кандидат психологических наук, доцент кафедры психологии РГУФКСМиТ

Ключевые слова: мозг, состояние мастера, экстремальные ситуации, функциональные асимметрии, спорт высших достижений.

Резюме: Проанализированы аспекты эмоционально-волевой подготовки к экстремальным ситуациям в восточных единоборствах и в спорте высших достижений с позиций современной психофизиологии. Рассмотрена близость таких понятий как «состояние мастера» в восточных единоборствах и «альфа-состояний», связанных с преобладанием альфа ритмов в деятельности мозга спортсмена. Отмечена необходимость учета индивидуальных особенностей спортсменов к экстремальным ситуациям с позиций межполушарной асимметрии.

\section{Psychophysiological aspects of emotional and volitional training for extreme situations (on the example of oriental martial arts)}

Moskvin Victor Anatolyevich

Russian University of Physical Education, Sport, Youth and Tourism

Dr.Psych., professor of psychology department of RSUPhCSYT

Moskvina Nina Victorovna

Russian University of Physical Education, Sport, Youth and Tourism

Ph.D., associate professor of psychology department of RSUPhCSYT

Keywords: brain, state master, extreme situations, functional asymmetry, elite sport.

Summary: The Analyzed aspects of emotional and volitional preparation for extreme situations in martial arts and in sports height-shih achievements in terms of modern psychophysiology. We consider the proximity of such concepts as "state of the master" in the martial arts and the "alpha state" associated with a predominance of alpha rhythms in the brain activity in sports psychology. The necessity of taking into account the individual characteristics of athletes to extreme situations from the standpoint of inter-hemispheric asymmetry. 
Введение. В спортивной психологии одной из фундаментальных проблем является проблема адаптации человека к экстремальным ситуациям [1-6]. В литературе профессиональная адаптация понимается как процесс, включающий физиологические, а также личностно-психологические, поведенческие и социальные компоненты. В статье предпринята попытка проанализировать особенности эмоционально-волевой подготовки к экстремальным ситуациям в восточных единоборствах [7] и в спорте высших достижений с позиций современной психофизиологии.

Постановка проблемы. В процессе подготовки будущему воину (самураю) необходимо было достичь состояния, при котором техника применяется рефлекторно и бессознательно. «Когда дух поглощен только выполнением техники, победа не достижима. Важно тренироваться, не сосредотачиваясь на мыслях об ударах или выпадах. Чтобы навык мог быть применен, ум и меч должны действовать как единое целое» [7].

Древние мастера говорили своим ученикам: «У идущего одна дорога, у ждущего тысячи», намекая на иллюзорность внешней формы движения и прохождения истинного выбранного пути каждого ученика [7]. В этой фразе хранилась великая истина, которую, правильно понимая, можно применить к жизни, «посмотреть в глубину» явления. Мастера использовали разные приемы и методы (в том числе, и медитацию) для введения тела в универсальное состояние покоя. Вводя себя в такое состояние, ученик приобретал колоссальную внешнюю и внутреннюю силу. Мастер давал ученику задание - «создать нечто напоминающее пустоту в сознании, как будто сразу после сна, проснулся, но еще не успел ни о чем подумать». Такое состояние позволяло практически никогда не уставать, даже при длительной физической нагрузке. Раскрытие таких способностей продолжались у человека на протяжении всей жизни. Однажды, найдя такое состояние, ученик старался держать его до самого конца занятий и вызывать при дальнейших тренировках. Все ощущения дополнялись энергетическими практиками, и их наработками в процессе занятий, что позволяло входить в нужное состояние мгновенно. Внезапно напасть на такого мастера было крайне непросто, а вывести из состояния равновесия было поистине сложно.

Существовали определенные принципы выполнения упражнений

- нельзя выполнять упражнения в плохом настроении

- только в расслабленном теле правильно течет внутренняя энергия

- тело должно быть сбалансировано по оси координат

- все движения подкрепляются мыслью и желанием его исполнить

- конечная фаза всех занятий отключение сознания (мыслей)

- при упадке сил не заставлять себя, а расслабиться

- в самостоятельных занятиях уделяется внимание основам

- перемещения ног по прямой с вращением по восьми сторонам

- движения с уходом в круг с пониманием понижения и перемещения центра 
- регулярное выполнение энергетических практик для увеличения энергии в нижнем киноварном поле

- объединение знаний в формы и создание собственных элементов

- помнить о постоянном расслаблении тела в состоянии легкости и покоя.

Когда эмоциональное состояние ученика приходило в норму, можно было начинать «заниматься». Начало этого «тайного» состояния не ждали, оно приходило само. Конечной целью мастера было помочь ученику превзойти ограниченность своего разума и изменить сознание для встречи с просветлением. Таким образом, эти особые состояния получили название «состояние мастера» и возникали чаще спонтанно после отработки техники владения мечом (или других боевых приемов) до высшего уровня, т.е. до уровня автоматизма.

Нечто подобное мы можем видеть и в современном спорте. Известно, что когда спортсмены достигают пика спортивной формы (ПСФ), у них возникает особое психофизиологическое состояние взаимодействия тела и сознания, которое позволяет легко достигать высоких уровней работоспособности. По самоотчетам спортсменов происходит изменение временной перспективы, их сознание заполнено только тем, что происходит в настоящем, в данный момент. Происходит полная концентрация на том, что происходит здесь и сейчас. Спортсмены, достигшие ПСФ, настолько целеустремленны, что они не отвлекаются ни на что, достигая, в то же время, очень высоких уровней работоспособности. Эти состояния близки «состояниям мастера» (которые описываются в восточных единоборствах) и с точки зрения современной психофизиологии их можно назвать альфасостояниями (по преобладанию альфа ритмов в активности мозга) [4].

Состояния ПСФ позволяет говорить о следующих его характеристиках:

- спокойное сознание и относительно расслабленное тело, описываемое как спокойная настороженность. Это особое состояние, когда тело и сознание функционируют как одно целое в одно время, независимо от любых внешних вмешательств или внутренних ощущений. Возникает чувство легкости работы, спортсмен отрешен от внешнего влияния и внутренних желаний;

- высокое значение соотношения уровней сигнал/шум. Сигнал, который значим для спортсмена, является объектом концентрации внимания и распознается лучше, чем все остальные сигналы. Концентрация внимания на значимом объекте выдвигает на первый план более тонкие его аспекты, заставляя казаться их большими и замедленными.

- полная фокусировка на существующем моменте, в основе которой лежит способность абстрагироваться от любых мыслей о прошлом или о будущем и фокусировать сознание полностью на существующем моменте, на выполнении конкретной задачи.

Спортсмены, ощутившие состояние ПСФ («состояние мастера») отмечают, что сама попытка произвольно войти в это состояние удается не 
всегда. Словесные и гипнотические методы воздействия на подсознание в данном случае являются временными и не способствуют изменению состояния сознания.

Состояние ПСФ сходно еще с одним, которое описывается как альтернативное состояние сознания (АСС). Еще в конце 1960-х гг. известный психолог G.Murphy [8] выделил тип альтернативного состояния сознания, который (в отличие от фармакологически вызванных, медитативных и гипнотических АCC) обозначил как «креативное АCС» (КАСС). Это состояние связанно с творческой активностью личности и достижением пика совершенства в различных видах деятельности: спорт, искусство, бизнес. Прогресс в познании КАСС произошел именно в спортивной науке. В настоящее время выделены следующие основные психологические и психофизиологические характеристики КАСС спортсменов:

- полная концентрация внимания на целевой установке (результат) в сочетании с диссоциацией от окружающей среды;

- изменение восприятия времени и пространства;

- снижение болевой чувствительности и снятие психологического барьера (трансформация оценки достижения цели);

- формирование яркого моторно-психического образа реализации спортивного навыка.

Обучение спортсменов самоиндукции КАСС составляет ключевое звено технологии психофизиологической подготовки, а выявление способности спортсмена к самоиндукции КАСС имеет большое значение в диагностике качества психической подготовки спортсмена. Одним из способов, катализирующих обучение этой технологии, может являться метод аудиовизуальной стимуляции (АВС) или т.н. метод применения майндмашин в сочетании с ментальным тренингом, который сегодня активно используется в спортивной психологии [4]. АВС-тренинги рассматриваются как способ психофизиологической тренировки человека, как возможность сенсорной нейроэндокринной активации коры головного мозга, что может помочь успешнее приспосабливаться к быстро изменяющимся ситуациям во время занятий спортом. Необходимо проведение дальнейших научных исследований по разработке мероприятий по коррекции психофизиологического состояния спортсменов в различных фазах тренировочного процесса и в соревновательный период с учетом специфики конкретных видов спорта, уровня тренированности спортсмена и индивидуальнотипологических особенностей (с учетом особенностей функциональных асимметрий мозга и индивидуальных профилей латеральности) [3-6].

Выводы. Полученные данные позволяют говорить о сходстве таких понятий как «состояние мастера» в восточных единоборствах и «альфа-состояния» в спортивной психологии, связанных с преобладанием альфа ритмов в деятельности мозга. Следует также отметить необходимость исследования индивидуальных особенностей спортсменов к экстремальным ситуациям с позиций межполушарной асимметрии.

Результаты могут быть использованы для анализа особенностей 
эмоционально-волевой подготовки в спортивной психологии и для прогнозирования поведения человека в экстремальных ситуациях.

Исследование выполнено при финансовой поддержке РГНФ, проект № 16-06-50146-а (ф).

\section{Литература}

1. Байковский Ю.В. Концепция разработки педагогической системы обеспечения безопасности деятельности человека в экстремальных условиях горной среды // Теория и практика прикладных и экстремальных видов спорта. - № 4 (19). - 2010. - С. 20-22.

2. Блеер А.Н. (ред.) Основы психофизиологии экстремальной деятельности /А.Н. Блеер - М.: ООО «Анита Пресс», 2006. - 380 с.

3. Москвин В.А., Москвина Н.В. Межполушарные асимметрии и индивидуальные различия человека. - М.: Смысл, 2011. - 368 с.

4. Москвин В.А., Москвина Н.В. Метод аудиовизуальной стимуляции как способ психофизиологической подготовки спортсменов // Спортивный психолог. - № 3. - 2009. - С. 54-59.

5. Москвин В.А., Москвина Н.В. Психофизиология индивидуальных различий в спорте. - М.: НИИ спорта РГУФКСМиТ, 2013. - 128 с.

6. Москвина Н.В. Индивидуальные стили реагирования на факторы стресса // Теория и практика прикладных и экстремальных видов спорта. - 2010. - № 4 (19).- С. 20-22.

7. Табата К. Секреты тактики: Уроки великих мастеров / Пер. с англ. - СПб.: Изд-во «ДИЛЯ», 2006. - 128 с.

8. Murphy G. Psychology in the Year 2000 // American Psychologist. 1969. - Vol. 24. - P. 523-530. 